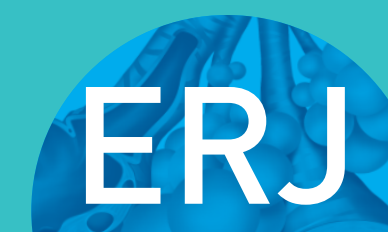

open research
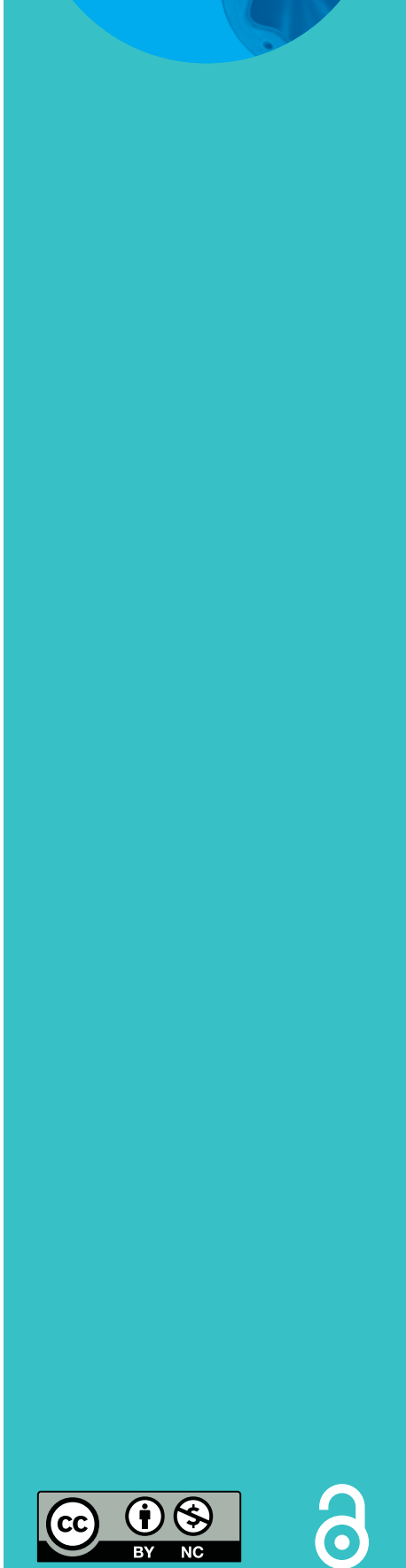

\section{Impact of detecting and treating exercise-induced bronchoconstriction in elite footballers}

\author{
Anna R. Jackson ${ }^{1,2}$, James H. Hull ${ }^{3,4}$, James G. Hopker ${ }^{1}$ and \\ John W. Dickinson ${ }^{1}$
}

Affiliations: ${ }^{1}$ School of Sport and Exercise Sciences, University of Kent, Chatham, UK. ${ }^{2}$ English Institute of Sport, London, UK. ${ }^{3}$ Dept of Respiratory Medicine, Royal Brompton Hospital, London, UK. ${ }^{4}$ National Heart and Lung Institute, Imperial College, London, UK.

Correspondence: John W. Dickinson, School of Sport and Exercise Sciences, University of Kent, Medway Building, Chatham, Kent, ME4 4AG, UK. E-mail: J.W.Dickinsonakent.ac.uk

ABSTRACT Our aim was to evaluate the prevalence of exercise-induced bronchoconstriction (EIB) in elite football players and assess subsequent impact of therapy on airway health and exercise performance.

97 male professional football players completed an airway health assessment with a eucapnic voluntary hyperpnoea $(\mathrm{EVH})$ challenge to diagnose EIB. Players demonstrating a positive result $\left(\mathrm{EVH}^{+}\right)$were prescribed inhaler therapy depending on severity, including inhaled corticosteroids and inhaled shortacting $\beta_{2}$-agonists, and underwent repeat assessment after 9 weeks of treatment. Eight players $\left(\mathrm{EVH}^{+} \mathrm{n}=3\right.$, $\left.\mathrm{EVH}^{-} \mathrm{n}=5\right)$ completed a peak oxygen uptake $\left(V^{\prime} \mathrm{O}_{2}\right.$ peak $)$ test at initial and follow-up assessment.

Out of the 97 players, 27 (28\%) demonstrated a positive EVH result. Of these, 10 had no prior history (37\%) of EIB or asthma. EVH outcome was not predictable by respiratory symptoms. Seven (24\%) of the $27 \mathrm{EVH}^{+}$players attended follow-up and demonstrated improved post-challenge spirometry (forced expiratory volume in $1 \mathrm{~s}$ pre-test $-22.9 \pm 15.4 \%$, post-test $-9.0 \pm 1.6 \% ; \mathrm{p}=0.018$ ). At follow-up $V^{\prime} \mathrm{O}_{2}$ peak improved by $3.4 \pm 2.9 \mathrm{~mL} \cdot \mathrm{kg}^{-1} \cdot \mathrm{min}^{-1}$ in $\mathrm{EVH}^{+}$players compared to $0.1 \pm 2.3 \mathrm{~mL} \cdot \mathrm{kg}^{-1} \cdot \mathrm{min}^{-1}$ in $\mathrm{EVH}^{-}$ players. Magnitude of inference analysis indicated treatment was possibly beneficial $(74 \%)$ for exercise capacity.

Elite football players have a high EIB prevalence. Treatment with inhaler therapy reduces EIB severity.

@ERSpublications

Screening and treating EIB in elite football players improves airway health and may improve exercise performance http://ow.ly/ngE530iWGJh

Cite this article as: Jackson AR, Hull JH, Hopker JG et al. Impact of detecting and treating exercise-induced bronchoconstriction in elite footballers ERJ Open Res 2018; 4: 00122-2017 [https:// doi.org/10.1183/23120541.00122-2017].

Received: Oct 022017 | Accepted after revision: March 022018

Copyright $\odot$ ERS 2018. This article is open access and distributed under the terms of the Creative Commons Attribution Non-Commercial Licence 4.0. 


\section{Introduction}

Exercise-induced bronchoconstriction (EIB) is now recognised to be highly prevalent in some groups of elite athletes [1,2] and can impair their health and exercise performance [3-6]. The nature of elite-level football suggests that EIB may be relevant and pose a particular risk to this group of athletes. Specifically, elite football players regularly sustain high ventilation rates [7] from a young age [8], while often training and competing in an asthmogenic environment, i.e. in cold air, high pollen and areas of high pollution. Despite this, little is currently known regarding the nature of EIB in professional football players.

Previous studies suggest that football players are often misdiagnosed or incorrectly labelled as having EIB or asthma [9], highlighting that respiratory symptoms are poorly predictive in the diagnosis of EIB and therefore limit the accuracy of a symptom-based approach to diagnosis [10]. However, there have been no prospective studies evaluating the prevalence of EIB, or indeed the benefits of treating EIB in this group of elite athletes.

It is recognised that EIB has deleterious effects on the efficiency of gas exchange [4], and therefore can impair performance. Indeed, STENSRUD et al. [5] report impaired oxygen uptake in individuals with EIB, and an improvement in peak oxygen uptake $\left(V^{\prime} \mathrm{O}_{2}\right.$ peak $)$ was reported in players of Australian Rules football following the initiation of treatment for previously undetected EIB [6].

Football clubs have a duty of care for their players; to protect their health while at the same time optimising their performance. There are rigorous medical guidelines in place which include screening players for certain medical conditions (e.g. cardiac abnormalities) [11]; however, clubs do not routinely assess players for EIB. Some authors have called for screening for EIB to be implemented [12, 13]; however, before a screening programme can be put in place, a number of stringent criteria must be met, including demonstrating prevalence, ability to detect the condition of interest and an understanding of the impact of intervention in the population of interest $[14,15]$.

The aim of this work was to address these deficiencies by using robust objective tests to provide a comprehensive assessment of the impact of EIB in professional football players by: 1) determining the prevalence of EIB in elite footballers; 2) assessing the impact of appropriate therapy on airway inflammation and EIB control; and 3) investigating the effect of treating players with EIB on exercise performance. In order to achieve this aim with a standardised and widely accepted approach, we utilised the bronchoprovocation methodology of eucapnic voluntary hyperpnoea (EVH) [16] testing to establish the presence of airway dysfunction and EIB. We hypothesised that EIB would be highly prevalent and that initiation of standard asthma therapy would be beneficial for airway health, as assessed by physiological measures of airway hyperreactivity and inflammation, and potentially for exercise performance.

\section{Methods}

\section{Study population}

Male professional football players from the English Football Premier League, Championship and League One were invited to participate in a detailed respiratory health assessment, as a component of their preseason medical examination in July, prior to their preseason training period.

\section{Study design}

All players attended for a detailed respiratory assessment, including screening for EIB using EVH challenge [17] (part 1). Subsequently, players with EIB were treated for 9 weeks, after which they had a follow-up respiratory assessment (part 2). A subgroup of players completed maximal exercise testing at both baseline and follow-up (part 3). All players were free from illness in the 2 weeks prior to assessment, and were requested to avoid exercise and caffeine for $\geqslant 4 \mathrm{~h}$ before assessment. Ethical approval for the study was obtained from the University of Kent School of Sport and Exercise Sciences Research ethics committee (144-2014_2015) and participants provided written consent.

\section{Part 1: baseline assessment}

Players completed a detailed respiratory assessment and initially completed a questionnaire to determine their medical history and evaluate presence of respiratory symptoms. Players previously prescribed medication for asthma/EIB $(n=7)$ were asked to withhold treatment at the time of assessment, in accordance with guideline recommendations [1].

\section{Respiratory assessment}

Airway inflammation was assessed by determining exhaled nitric oxide fraction (FeNO) (NIOX VERO; Aerocrine, Uppsala, Sweden) [18] and lung function was assessed by maximal flow volume spirometry (Spiro-USB and MicroLab; CareFusion, Hoechberg, Germany) [19]. 
An EVH challenge was then conducted, as described previously [1]. In brief, players were required to inspire medical-grade air ( $21 \%$ oxygen, $5 \%$ carbon dioxide and $74 \%$ nitrogen with $<2 \%$ humidity) for $6 \mathrm{~min}$ at a target ventilation rate of $85 \%$ maximal voluntary ventilation (MVV). Target MVV was calculated as $30 \times$ forced expiratory volume in $1 \mathrm{~s}$ (FEV1) [20] and minute ventilation was recorded. Maximal flow volume loops were measured in duplicate at 3, 5, 7, 10 and 15 min post-EVH, with the flow loop with the best FEV1 accepted at each time point. A test was considered positive for EIB if FEV1 fell by $\geqslant 10 \%$ from baseline at two consecutive time points. At this point, $4 \times 100 \mu \mathrm{g}$ of inhaled salbutamol was administered using a metered dose inhaler and maximal flow volume loops were recorded $15 \mathrm{~min}$ post-inhalation.

Severity of EIB was classified as mild, moderate or severe, dependent on the fall in FEV1 post-EVH $\left(10-<25 \%, 25-<40 \%\right.$ and $\geqslant 40 \%$, respectively) [21]. Players with a positive EVH challenge $\left(\mathrm{EVH}^{+}\right)$test were then prescribed medication by their team physician, in accordance with recommendations [22], with a spacing device and inhaler technique advice [23].

\section{Treatment}

Medication was prescribed according to EIB severity; players with mild EIB were prescribed a daily inhaled corticosteroid (ICS), in conjunction with an inhaled short-acting $\beta_{2}$-agonist (SABA), as needed. Those with moderate EIB were prescribed a combination inhaler containing ICS and a long-acting $\beta_{2}$-agonist, with a SABA as needed. Finally, players with severe EIB were prescribed the combination inhaler with the addition of a daily montelukast and a SABA as required.

Part 2: follow-up assessment

Players continued with their usual preseason training and no change was made to training load. After 9 weeks, $\mathrm{EVH}^{+}$players underwent a further respiratory assessment (as detailed earlier).

\section{Part 3: performance assessment}

A subgroup of players $(\mathrm{n}=8)$ completed a $V^{\prime} \mathrm{O}_{2}$ peak test on a motorised treadmill with simultaneous gas analysis (Oxycon Pro; Jaeger, Hoechberg, Germany). Initial running speed was set at $11 \mathrm{~km} \cdot \mathrm{h}^{-1}$ and a gradient of $1 \%$. Speed increased $1 \mathrm{~km} \cdot \mathrm{h}^{-1}$ every $3 \mathrm{~min}$ to $16 \mathrm{~km} \cdot \mathrm{h}^{-1}$, at which point the gradient was increased by $1 \%$ every minute until volitional exhaustion. $V^{\prime} \mathrm{O}_{2}$ peak was determined as the single highest 30-s average in $V^{\prime} \mathrm{O}_{2}$.

\section{Statistical analysis}

Data are presented as mean \pm SD unless otherwise stated. Players were grouped according to the result of their EVH challenge $\left(\mathrm{EVH}^{+}, \mathrm{EVH}^{-}\right)$. Group differences and pre- to post- data were analysed using independent or paired t-tests or the non-parametric equivalent and symptom data were analysed using Chi-squared analysis and Fisher's exact test. Given the small number of subjects completing performance assessment, magnitude-base inference analysis was utilised, using the spreadsheet from HopKINs [24] to assess the clinical impact of detection and treatment of EIB. All other analyses were conducted using SPSS software (version 23; SPSS, Chicago, IL, USA) with significance accepted at $\mathrm{p}<0.05$.

\section{Results}

98 players (age $24 \pm 4$ years, height $183 \pm 7 \mathrm{~cm}$, mass $80.3 \pm 7.2 \mathrm{~kg}$ ) completed the initial respiratory assessment; however, one player was subsequently excluded due to his inability to perform reliable spirometry (table 1). 17 players reported a previous diagnosis of asthma and/or EIB, of whom only seven were currently prescribed medication. 16 players reported troublesome respiratory symptoms, including cough, wheeze and dyspnoea at a frequency of $5 \%, 3 \%$ and $8 \%$, respectively.

\section{Part 1: baseline assessment}

Pulmonary function, inflammation and EIB

Lung function was normal in all players at the baseline assessment, with no evidence of significant airflow obstruction (FEV1 $>70 \%$ predicted). In 39 (40\%) players FeNO was raised above normal (>25 ppb), with 19 (20\%) players having a value $>50 \mathrm{ppb}$ (table 1$)$.

A positive EVH result was found in $27(28 \%)$ players, of which the majority $(n=21,78 \%)$ were classified as having a mild response and fewer having a moderate $(n=4,15 \%)$ or severe $(n=2,7 \%)$ response (figure 1$)$. All $\mathrm{EVH}^{+}$players demonstrated a subsequent improvement in $\mathrm{FEV} 1$ following administration of bronchodilator treatment (change in FEV1 20.6 $\pm 11.6 \%$, range 6-40\%; $\mathrm{p}<0.001$ ). There was a weak inverse relationship between $\mathrm{FeNO}$ and percentage fall in $\mathrm{FEV} 1$ post-EVH $\left(\mathrm{r}_{\mathrm{s}}-0.24, \mathrm{p}=0.02\right)$, i.e. the greater the $\mathrm{FeNO}$ the larger the reduction in lung function post-EVH. 
TABLE 1 Player characteristics and baseline respiratory assessment data for the 97 players who performed the baseline eucapnic voluntary hyperpnoea (EVH) challenge

\begin{tabular}{|c|c|c|c|c|}
\hline & All players & $\mathrm{EVH}^{+}$ & $\mathrm{EVH}^{-}$ & p-value $\mathrm{EVH}^{+}$versus $\mathrm{EVH}^{-}$ \\
\hline Subjects & 97 & 27 & 70 & \\
\hline Age years & $24 \pm 4$ & $24 \pm 4$ & $24 \pm 4$ & 0.56 \\
\hline Height $\mathrm{cm}$ & $182.6 \pm 6.8$ & $183.0 \pm 6.7$ & $182.5 \pm 6.9$ & 0.77 \\
\hline Weight kg & $80.3 \pm 7.2$ & $80.7 \pm 6.3$ & $80.2 \pm 7.5$ & 0.73 \\
\hline FenO ppb & $21.0(24.6)$ & $36.0(63.0)$ & $18.8(17.3)$ & $<0.01^{\#}$ \\
\hline FEV 1 L & $4.71 \pm 0.65$ & $4.51 \pm 0.55$ & $4.78 \pm 0.68$ & 0.07 \\
\hline FVC L & $5.67 \pm 0.76$ & $5.68 \pm 0.64$ & $5.67 \pm 0.81$ & 0.95 \\
\hline PEF L·min ${ }^{-1}$ & $630.0(135.0)$ & $616.0(102.0)$ & $635.0(148.8)$ & $0.29^{\#}$ \\
\hline FEV $1 / F V C$ & $82.7 \pm 6.8$ & $79.3 \pm 8.0$ & $84.1 \pm 5.8$ & 0.01 \\
\hline MVV during EVH \% predicted & $77.68 \pm 11.76$ & $83.07 \pm 10.88$ & $75.54 \pm 11.48$ & $<0.01$ \\
\hline Fall FEV 1 from EVH \% & $-8(5.5)$ & $-13(10.0)$ & $-6(4.0)$ & $<0.01^{\#}$ \\
\hline
\end{tabular}

Data are presented as $\mathrm{n}$, mean $\pm \mathrm{SD}$ or median (interquartile range), unless otherwise stated. FeNO: exhaled nitric oxide fraction; FEV1: forced expiratory volume in $1 \mathrm{~s}$; FVC: forced vital capacity; PEF: peak expiratory flow; MVV: maximal voluntary ventilation. " : data analysed using Mann-Whitney U-tests.

\section{Relationship between EVH result and prior diagnosis and symptoms}

Only $10(37 \%)$ of the $\mathrm{EVH}^{+}$players reported a history of asthma and/or EIB and four (15\%) of those were currently prescribed asthma medication. Although respiratory symptoms were reported frequently, there was no relationship between the presence of symptoms and likelihood of a positive EVH result (table 2). Moreover, the most severe EVH result (49\% reduction in $\mathrm{FEV}_{1}$ ) was observed in a player with no prior history of airways disease or current respiratory symptoms.

\section{Part 2: follow-up assessment}

After 9 weeks, only 11 of the $27(41 \%) \mathrm{EVH}^{+}$players attended for the follow-up visit. Reasons for not attending included club not permitting time for the medical team to schedule follow-up, not believing it was necessary, away for international competition, injured, and not wanting to repeat the EVH test. A further four players were excluded from follow-up analysis due to them not taking medication as prescribed.

No difference was seen in resting FEV1 between baseline and follow-up visits (table 3); however, FeNO was lower at follow-up $(\mathrm{p}=0.043)$ (table 3, figure 2a). In addition, there was a reduction $(\mathrm{p}=0.02)$ in the percentage fall in FEV1 following $\mathrm{EVH}$ and this was apparent despite players achieving a similar total ventilation during the challenge tests (table 3, figure 2b). Moreover, all but two players had a negative $\mathrm{EVH}$ test at the second visit (i.e. fall in $\mathrm{FEV}_{1}<10 \%$ post-challenge). Despite these findings, two (29\%) of the seven players reported an increase in symptoms.

\section{Part 3: performance assessment}

All treated $\mathrm{EVH}^{+}$players $(\mathrm{n}=3)$ showed an improvement in $V^{\prime} \mathrm{O}_{2}$ peak (pre $50.60 \pm 5.65 \mathrm{~mL} \cdot \mathrm{kg}^{-1} \cdot \mathrm{min}^{-1}$, post $53.98 \pm 2.80 \mathrm{~mL} \cdot \mathrm{kg}^{-1} \cdot \mathrm{min}^{-1}$ ) (figure 3 ); however, the magnitude of this change was not significant

FIGURE 1 Maximum fall in forced expiratory volume in $1 \mathrm{~s}$ (FEV 1 ] following eucapnic voluntary hyperpnoea $(\mathrm{EVH})$ challenge

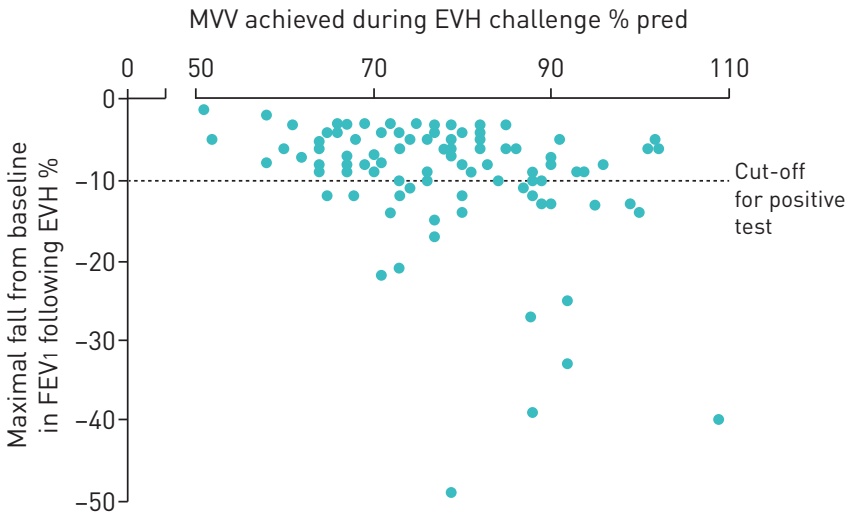




\begin{tabular}{lccccccc} 
TABLE 2 Respiratory symptoms reported by players & No & $\begin{array}{c}\text { No } \\
\text { symptoms }\end{array}$ & Coughing & $\begin{array}{c}\text { Excessive } \\
\text { mucus } \\
\text { symptom }\end{array}$ & $\begin{array}{c}\text { Chest } \\
\text { tightness }\end{array}$ & $\begin{array}{c}\text { Difficulty } \\
\text { breathing }\end{array}$ & Wheezing \\
\hline $\mathbf{E V H}^{+}$ & $19(70)$ & $8(30)$ & $1(4)$ & $1(4)$ & $2(7)$ & $4(15)$ & $1(4)$ \\
$\mathbf{E V H}^{-}$ & $60(89)$ & $8(11)$ & $4(6)$ & $1(1)$ & $2(3)$ & $4(6)$ & $2(3)$ \\
p-value & 0.06 & 0.06 & 1.00 & 0.50 & 0.32 & 0.22 & 1.00
\end{tabular}

Data are presented as $n(\%)$, unless otherwise stated. $n=95 ; n=2$ did not complete questionnaires. EVH: eucapnic voluntary hyperpnoea.

$(\mathrm{p}=0.184)$. Three $\mathrm{EVH}^{-}$players had a decrease in $V^{\prime} \mathrm{O}_{2}$ peak and two demonstrated an improvement (pre $53.06 \pm 2.14 \mathrm{~mL} \cdot \mathrm{kg}^{-1} \cdot \mathrm{min}^{-1}$, post $\left.53.15 \pm 2.38 \mathrm{~mL} \cdot \mathrm{kg}^{-1} \cdot \mathrm{min}^{-1}\right)$. No significant difference was found in the change in $V^{\prime} \mathrm{O}_{2}$ peak between the two groups $(\mathrm{p}=0.13) ; \mathrm{EVH}^{+}$players had an improvement of $3.38 \pm 2.93 \mathrm{~mL} \cdot \mathrm{kg}^{-1} \cdot \mathrm{min}^{-1}$ and $\mathrm{EVH}^{-}$players improved by $0.09 \pm 2.30 \mathrm{~mL} \cdot \mathrm{kg}^{-1} \cdot \mathrm{min}^{-1}$; however, the effect of treatment on maximal exercise capacity, from magnitude-base inference analysis, was found to be possibly beneficial (74.1\%).

\section{Discussion}

In a cohort of elite football players completing a preseason medical screening we found a high prevalence of both respiratory symptoms and airway dysfunction. Indeed, by employing a widely accepted bronchoprovocation methodology [17], namely EVH testing, we found that approximately one-third of this prospectively screened cohort of elite football players had evidence of EIB. Moreover, subsequent treatment with appropriate therapy was associated with a clear attenuation in airway dysfunction and improvement in markers of airway inflammation and hyperreactivity. In addition, all treated players demonstrated an improvement in peak exercise capacity.

The high prevalence of EIB in elite footballers observed in this study concurs with previous smaller-scale studies that have reported a prevalence of between 29\% [25] and 51\% [9] in this group of athletes. Dickinson et al. [25] included only a small sample of one elite football team $(n=21)$, while ANSLEY et al. [9] studied a highly selected population of football players using inhaler therapy. Thus, this is the first study to truly assess prevalence in a prospective "medical screening"-type scenario across several elite football teams.

The study findings are consistent with other studies demonstrating a heightened prevalence of airway dysfunction in running-based sports [1]. In addition, they highlight again the poor predictive value of symptoms in the diagnosis of EIB $[10,26]$. Indeed "undetected" EIB was found in 63\% of players, and no single symptom or combination of symptoms was predictive of the presence of EIB. Accordingly, it is concerning that there appears to be a high proportion of professional footballers currently training and playing with undiagnosed and uncontrolled EIB. Moreover, in keeping with our previous study [9], we found evidence of players with a prior diagnosis of EIB/asthma that was incorrect and not supported by the objective test findings. Indeed $71 \%$ of players with a prior diagnosis and treatment plan were either over- or under-medicated.

TABLE 3 Differences before and after treatment in eucapnic voluntary hyperpnoea $(E V H)^{+}$players on medication

\begin{tabular}{|c|c|c|c|}
\hline & Pre-treatment & Post-treatment & p-value \\
\hline FeNO ppb & $85.1 \pm 60.7$ & $27.5 \pm 10.91$ & 0.04 \\
\hline Baseline FEV 1 L & $4.41 \pm 0.55$ & $4.25 \pm 0.32$ & 0.23 \\
\hline MVV during EVH \% predicted & $85.29 \pm 13.61$ & $87.81 \pm 13.58$ & 0.38 \\
\hline Fall in FEV1 post-EVH \% & $14(28.0)$ & $8(9.0)$ & $0.02^{\#}$ \\
\hline
\end{tabular}

Data are presented as mean \pm SD or median (interquartile range), unless otherwise stated. Bold type represents statistical significance. FeNO: exhaled nitric oxide; FEV1: forced expiratory volume in $1 \mathrm{~s}$; MVV: maximal voluntary ventilation. ${ }^{\#}$ : data analysed using sign exact tests. 

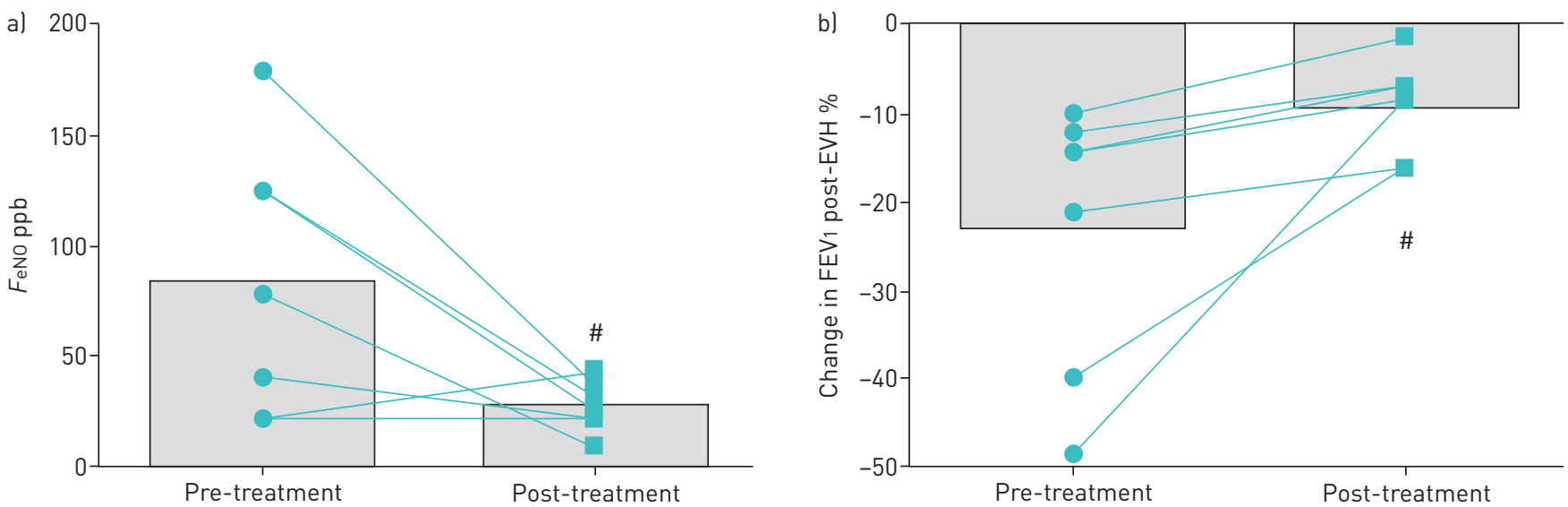

FIGURE 2 a) Exhaled nitric oxide fraction ( $F_{\mathrm{eNO}}$ ) before and after 9 weeks of treatment; b) percentage change in forced expiratory volume in $1 \mathrm{~s}$ (FEV 1 ) following eucapnic voluntary hyperpnoea (EVH) challenge before and after 9 weeks of treatment. Data are presented as mean and individual values. ${ }^{\#}$ : $p<0.05$ versus pre-treatment.

In addition, it is apparent that respiratory symptoms are not useful in predicting the airway response following treatment [27]. Specifically, we found that despite a reduction in the fall in FEV1 post-EVH challenge, almost one-third of players with EIB reported an increase in symptoms at the follow-up assessment. This is in keeping with the findings of SIMPSON et al. [28], who reported that half the athletes assessed reported at least one ongoing respiratory symptom despite their fall in FEV1 post-EVH being blunted by the use of inhaled terbutaline. Indeed, in this study $28 \%$ had a higher symptom score when this fall was blunted. These findings act to emphasise the poor relationship between the presence of respiratory symptoms and airway dysfunction and highlight our current limited understanding of the pathophysiological mechanisms underpinning airway-centric symptoms in athletes [29]. Furthermore, it serves to promote the importance of other conditions, such as exercise-induced laryngeal obstruction, which may coexist with EIB and cause symptoms [30, 31].

In the current study, we repeated objective testing 9 weeks after EIB therapy was initiated to ensure adequate control of EIB [17]. Data from this follow-up assessment reveals that standard asthma therapy can improve EIB and airway inflammation. Although treatment was recommended for all $27 \mathrm{EVH}^{+}$ athletes, only seven took the medication as prescribed. This represents an attrition rate of $74 \%$, which suggests a degree of resistance to football players engaging in therapy for this condition. Certainly, anecdotally, EIB often appears to be discounted as medically relevant by medical staff in football squads and viewed as of secondary importance to cardiac screening [32]. Hopefully, our findings challenge this presumption and provide the supporting basis to educate both players and team clinicians regarding the importance of EIB in elite football players. Our work acts to address some of the concerns regarding screening athletes for airway dysfunction [15] and certainly suggests that focus on airway health is

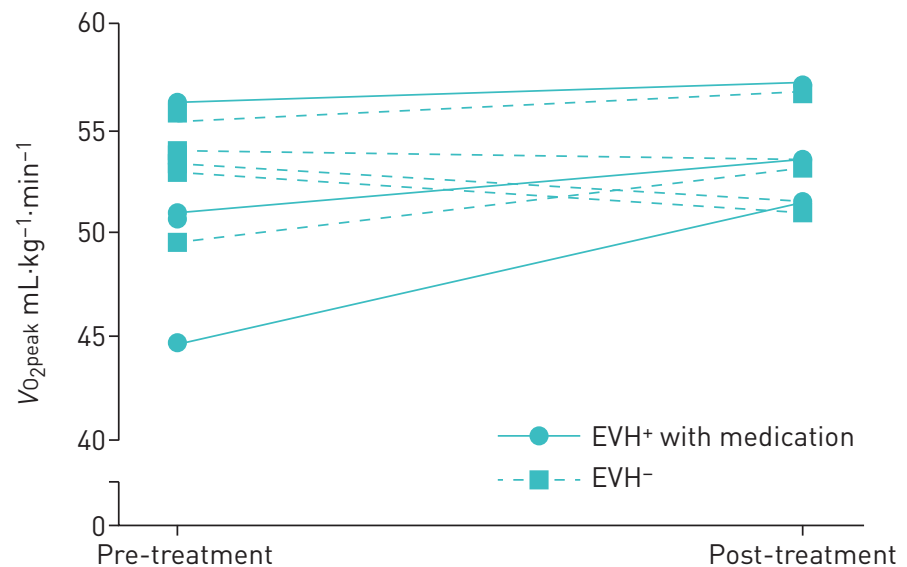

FIGURE 3 Peak oxygen uptake $\left(V^{\prime} \mathrm{O}_{2}\right.$ peak $)$ before and following 9 weeks of treatment. EVH: eucapnic voluntary hyperpnoea. 
important in football players, given the work suggesting that EIB in endurance athletes could be considered akin to an occupational lung disease [33].

A key driving factor in elite sport is the impact of any intervention (e.g. screening or new treatment) on athlete performance, and in addition to improving airway health, treating EIB may be beneficial for performance. Studying performance impact at the elite level is clearly complex, with multiple potential confounding factors and very few footballers completed this component of our study for the above-mentioned reasons, meaning this section of our data is difficult to interpret. Although not statistically significant, $\mathrm{EVH}^{+}$players had mean increase in $V^{\prime} \mathrm{O}_{2}$ peak of $7.2 \%$, whereas $\mathrm{EVH}^{-}$players had only a $0.24 \%$ increase over the same time period, with the observed increases in $V^{\prime} \mathrm{O}_{2}$ peak bringing the performance of the $\mathrm{EVH}^{+}$players in line with $\mathrm{EVH}^{-}$players. As previously stated, due to the small sample size, these results should be interpreted with caution and future research should aim to follow this up with an adequately powered study. Similar findings have been reported in sports with similar demands. BRUKNER et al. [6] found that players of Australian Rules football with newly diagnosed EIB had a significant improvement $(9 \%)$ in the $V^{\prime} \mathrm{O}_{2}$ peak following 6 weeks of treatment compared to controls. In addition, SPITER et al. [34] demonstrated that appropriately medicating elite rugby players with previously undiagnosed EIB improved their performance in a rugby-specific aerobic exercise challenge by $8 \%$ over the course of 12 weeks compared to $6 \%$ in the control group; however, this was not a significant finding. It has been hypothesised that this impact on performance may be due in part to bronchoconstriction during and following exercise resulting in reduced alveolar ventilation and efficiency of alveolar-to-arterial blood oxygen exchange [4].

\section{Methodological considerations}

A key limitation of this study is that our findings represent the result of a cross-sectional assessment. Specifically, players were not studied in a prospective randomised placebo-controlled fashion and thus our results have to be interpreted in view of their pragmatic limitations. Due to the elite nature of the football players involved, clubs would not allow us to withhold medication from those who needed it, or provide a placebo medication to those who did not. Moreover, players are subject to antidoping regulations and need to know exactly what they are taking at all times. In addition, we recognise that diagnosis of EIB from a one-off test is not entirely robust [35]; however, due to time restraints imposed by the clubs and the large numbers of players to screen, it would not have been practical to perform multiple tests. Our report replicates how a screening programme would work in "real-life", and is similar to the way football players are currently screened for cardiac conditions.

During the EVH test, the \%MVV achieved was significantly lower among $\mathrm{EVH}^{-}$players than among $\mathrm{EVH}^{+}$players; however, both groups achieved a $\mathrm{MVV}>60 \%$ which is required for an adequate test [36], and we think it is most unlikely that the mean difference of $8 \%$ between groups would explain the major findings of this study.

The study was initially powered based on $\sim 30 \%$ of players being found to have evidence of EIB. Initial power calculations showed that $15 \mathrm{EVH}^{+}$players were required to detect a $10 \%$ change in $\mathrm{FEV}_{1}$ in follow-up assessments. To accommodate for an anticipated high dropout rate in this population, we deliberately over-recruited. However, even with a sample size of 97 players, the high dropout rate meant that our study was under-powered.

As discussed, it was difficult for us to follow-up $\mathrm{EVH}^{+}$players and clearly it would have been desirable to significantly increase the number of players undergoing repeat assessment, including performance assessment. It may be possible to reduce the attrition rate by working with subelite cohorts or academy players; however, this limits potential generalisation to the elite population. Players and medical staff at clubs are under huge pressures from clubs and it is hard for them to allocate time for follow-up testing. At the follow-up assessment, it became evident that despite support from coaching and medical staff, many players had decided not to take the inhalers, and there was some confusion among these players regarding what they should be taking and when. Miller et al. [37] highlights the importance of educating coaching staff in the management of asthma and this may be an area which needs to be addressed when establishing a screening programme. For a screening programme to be effective in elite-level football, time needs to be invested in educating players about EIB and its treatment. Although there is a lack of evidence in the athletic population, it is clear that educational interventions can have a positive effect on clinical patients' asthma management [38]. Therefore, it is vital to have the cooperation of players at the start of the treatment.

\section{Conclusion}

In conclusion, this study revealed that approximately one-third of a cohort of elite football players appear to have EIB when screened for respiratory dysfunction at a preseason medical assessment, which in the 
majority of cases was not predictable by symptom-based assessment. Treatment of screen-detected EIB ${ }^{+}$ players resulted in improved airway inflammation and reduced airway hyperresponsiveness. Overall, the findings support the use of improved diagnostic testing for airway dysfunction in elite football players and highlight the importance of educating both players and football medical staff regarding this condition.

Acknowledgements: The authors are grateful to the football club players and medical staff for participating in and contributing to the study. We also like to thank Irisz Levai, Will Gowers, Tim Wheeler and Sarah Coakley (School of Sport and Exercise Sciences, University of Kent, Chatham, UK) for their assistance with data collection.

Conflict of interest: None declared.

\section{References}

1 Dickinson J, McConnell A, Whyte G. Diagnosis of exercise-induced bronchoconstriction: eucapnic voluntary hyperpnoea challenges identify previously undiagnosed elite athletes with exercise-induced bronchoconstriction. $\mathrm{Br}$ J Sports Med 2011; 45: 1126-1131.

2 Levai $\mathrm{IK}$, Hull $\mathrm{JH}$, Loosemore $\mathrm{M}$, et al. Environmental influence on the prevalence and pattern of airway dysfunction in elite athletes. Respirology 2016; 21: 1391-1396.

3 Becker JM, Rogers J, Rossini G, et al. Asthma deaths during sports: report of a 7-year experience. J Allergy Clin Immunol 2004; 113: 264-267.

4 Haverkamp HC, Dempsey JA, Pegelow DF, et al. Treatment of airway inflammation improves exercise pulmonary gas exchange and performance in asthmatic subjects. J Allergy Clin Immunol 2007; 120: 39-47.

5 Stensrud T, Berntsen S, Carlsen KH. Exercise capacity and exercise-induced bronchoconstriction (EIB) in a cold environment. Respir Med 2007; 101: 1529-1536.

6 Brukner P, Holzer K, Davies L, et al. The impact of exercise-induced bronchoconstriction on exercise performance. Med Sci Sport Exerc 2007; 39: S30.

$7 \quad$ Bangsbo J. Energy demands in competitive soccer. J Sports Sci 1994; 12: S5-S12.

8 Read PJ, Oliver JL, De Ste Croix MBA, et al. The scientific foundations and associated injury risks of early soccer specialisation. J Sports Sci 2016; 34: 2295-2302.

9 Ansley L, Kippelen P, Dickinson J, et al. Misdiagnosis of exercise-induced bronchoconstriction in professional soccer players. Allergy 2012; 67: 390-395.

10 Rundell KW, Im J, Mayers LB, et al. Self-reported symptoms and exercise-induced asthma in the elite athlete. Med Sci Sports Exerc 2001; 33: 208-213.

11 UEFA. UEFA Medical Regulations. Nyon, UEFA, 2014. www.uefa.com/MultimediaFiles/Download/Tech/uefaorg/ General/02/11/35/23/2113523_DOWNLOAD.pdf

12 Dickinson J, Whyte G, McConnell A, et al. Impact of changes in the IOC-MC asthma criteria: a British perspective. Thorax 2005; 60: 629-632.

13 Holzer K, Brukner P. Screening of athletes for exercise-induced bronchoconstriction. Clin J Sport Med 2004; 14: 134-138.

14 Wilson JMG, Jungner G. Principles and Practice of Screening for Disease. Geneva, World Health Organization, 1968. http://apps.who.int/iris/bitstream/10665/37650/17/WHO_PHP_34.pdf

15 Hull JHK, Ansley L, Garrod R, et al. Exercise-induced bronchoconstriction in athletes - should we screen? Med Sci Sports Exerc 2007; 39: 2117-2124.

16 Hull JH, Ansley L, Price OJ, et al. Eucapnic voluntary hyperpnea: gold standard for diagnosing exercise-induced bronchoconstriction in athletes? Sport Med 2016; 46: 1083-1093.

17 Weiler JM, Brannan JD, Randolph CC, et al. Exercise-induced bronchoconstriction update - 2016. J Allergy Clin Immunol 2016; 138: 1292-1295.

18 Dweik RA, Boggs PB, Erzurum SC, et al. An official ATS clinical practice guideline: interpretation of exhaled nitric oxide levels ( $F \mathrm{eNO}$ ) for clinical applications. Am J Respir Crit Care Med 2011; 184: 602-615.

19 Miller MR, Hankinson J, Brusasco V, et al. Standardisation of spirometry. Eur Respir J 2005; 26: 319-338.

20 Argyros G, Roach J, Hurwitz K, et al. Eucapnic voluntary hyperventilation as a bronchoprovocation technique: development of a standardized dosing schedule in asthmatics. Chest 1996; 109: 1520-1524.

21 Anderson SD, Kippelen P. Assessment of EIB: what you need to know to optimize test results. Immunol Allergy Clin North Am 2013; 33: 363-380.

22 Parsons JP, Hallstrand TS, Mastronarde JG, et al. An official American Thoracic Society clinical practice guideline: exercise-induced bronchoconstriction. Am J Respir Crit Care Med 2013; 187: 1016-1027.

23 van der Palen J, Klein JJ, Kerkhoff $\mathrm{AH}$, et al. Evaluation of the effectiveness of four different inhalers in patients with chronic obstructive pulmonary disease. Thorax 1995; 50: 1183-1187.

24 Hopkins WG. A spreadsheet for deriving a confidence interval, mechanistic inference and clinical inference from a p value. Sportscience 2007; 11: 16-20.

25 Dickinson J, Drust B, Whyte G, et al. Screening English Premier League football players for exercise-induced bronchoconstriction. In: Hiroyuki N, Drust B, Dawson B, eds. Science and Football VII: the Proceedings of the Seventh World Congress on Science and Football. Abingdon: Routledge, 2013; pp. 341-346.

26 Turcotte H, Langdeau JB, Thibault G, et al. Prevalence of respiratory symptoms in an athlete population. Respir Med 2003; 97: 955-963.

27 Brannan JD, Koskela H, Anderson SD. Monitoring asthma therapy using indirect bronchial provocation tests. Clin Respir J 2007; 1: 3-15.

28 Simpson AJ, Romer LM, Kippelen P. Self-reported symptoms after induced and inhibited bronchoconstriction in athletes. Med Sci Sports Exerc 2015; 47: 2005-2013.

29 Hull JH, Dickinson JW, Jackson AR. Cough in exercise and athletes. Pulm Pharmacol Ther 2017; 49-55.

30 Nielsen EW, Hull JH, Backer V. High prevalence of exercise-induced laryngeal obstruction in athletes. Med Sci Sports Exerc 2013; 45: 2030-2035.

31 Hall A, Thomas M, Sandhu G, et al. Exercise-induced laryngeal obstruction: a common and overlooked cause of exertional breathlessness. Br J Gen Pract 2016; 66: e683-e685. 
32 Hull JH, Rawlins JC. Screening for cardiac and respiratory problems in elite sport - compare and contrast. Expert Rev Respir Med 2016; 10: 715-717.

33 Price OJ, Ansley L, Menzies-Gow A, et al. Airway dysfunction in elite athletes - an occupational lung disease? Allergy 2013; 68: 1343-1352.

34 Spiteri DB, Dickinson JW, Greenwell J, et al. Impact of exercise-induced bronchoconstriction on athletic performance and airway health in rugby union players. Int Sport J 2014; 15: 333-342.

35 Price OJ, Ansley L, Hull JH. Diagnosing exercise-induced bronchoconstriction with eucapnic voluntary hyperpnea: is one test enough? J Allergy Clin Immunol Pract 2015; 3: 243-249.

36 Anderson SD, Argyros GJ, Magnussen H, et al. Provocation by eucapnic voluntary hyperpnoea to identify exercise induced bronchoconstriction. Br J Sports Med 2001; 35: 344-347.

37 Miller MG, Weiler JM, Baker R, et al. National Athletic Trainers' Association position statement: management of asthma in athletes. J Athl Train 2005; 40: 224-245.

38 Gibson PG, Powell H, Coughlan J, et al. Self-management education and regular practitioner review for adults with asthma. Cochrane Database Syst Rev 2003; 1: CD001117. 